INTERNATIONAL MONETARY FUND
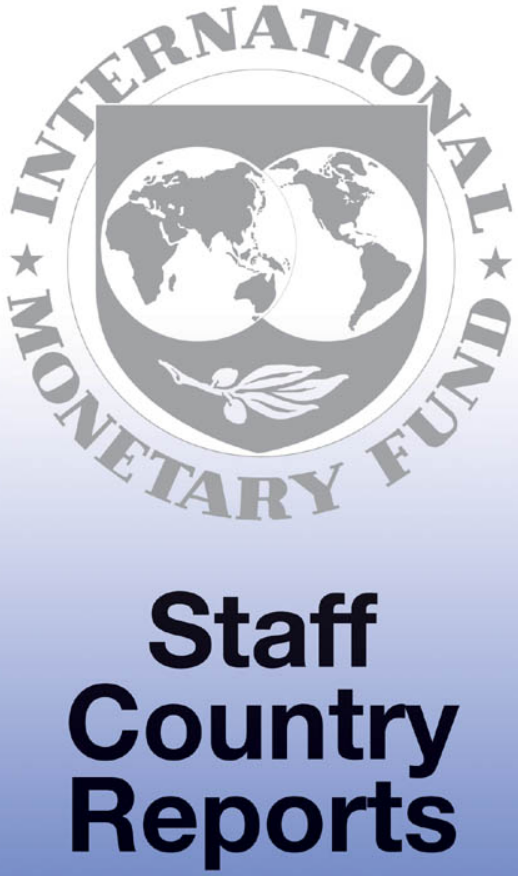


\section{Kingdom of the Netherlands-Netherlands: Technical Note: The Netherlands Model of Financial Sector Supervision}

This Technical Note on the Kingdom of the Netherlands-Netherlands Model of Financial Sector Supervision was prepared by a staff team of the International Monetary Fund as background documentation for the periodic consultation with the member country. It is based on the information available at the time it was completed in September 2004. The views expressed in this document are those of the staff team and do not necessarily reflect the views of the government of the Kingdom of the Netherlands - Netherlands or the Executive Board of the IMF.

The policy of publication of staff reports and other documents by the IMF allows for the deletion of market-sensitive information.

To assist the IMF in evaluating the publication policy, reader comments are invited and may be sent by e-mail to publicationpolicy@imf.org.

Copies of this report are available to the public from

International Monetary Fund $\bullet$ Publication Services

700 19th Street, N.W. • Washington, D.C. 20431

Telephone: (202) 6237430 • Telefax: (202) 6237201

E-mail: publications@imf.org • Internet: http://www.imf.org

Price: $\$ 15.00$ a copy

International Monetary Fund

Washington, D.C. 
This page intentionally left blank

CInternational Monetary Fund. Not for Redistribution 
FinANCIAL Sector Assessment Program

\section{THE KINGDOM OF THE NETHERLANDS- NETHERLANDS}

\section{TeChNical Note: The NeTHERlands Model of FINANCIAL SECTOR SUPERVISION}

SEPTEMBER 2004 


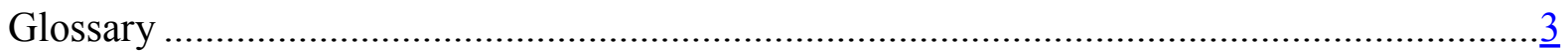

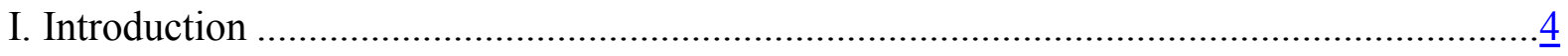

II. Adoption of Cross-Sectoral Functional Supervision........................................................

III. The Netherlands Framework....................................................................................

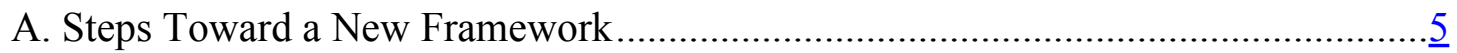

B. Design and Rationale of the Netherlands Framework ………................................

IV. Making the Model Work ..................................................................................... 


\section{GLOSSARY}

AFM

APRA

AML/CFT

DNB

EU

FSA

LCFI

PVK

RFT

STE
Authority for Financial Markets (Autoriteit Financiële Markten)

Australian Prudential Regulatory Authority

Anti-money laundering/Counter financing of terrorism

Netherlands Central Bank (De Nederlandsche Bank)

European Union

\section{Financial Services Authority}

Large, complex financial institution

Pension and Insurance Supervisor (Pensioen-en Verzekeringskamer)

Council of Financial Supervisors (Raad van Financiële Toezichthouders)

Securities Supervisor (Stichting Toezicht Effectenverkeer) 


\section{INTRODUCTION ${ }^{1}$}

1. This note discusses the new framework for financial sector surveillance and supervision being adopted in the Netherlands. The cross-sectoral approach being taken is at the forefront of the design of supervisory systems, and may well serve as a model for supervisory system reforms in other countries. The Netherlands authorities have invested considerable thought and effort in designing and implementing the new institutional framework, and we expect that it will make an important contribution to ensuring continued effective supervision as the financial system evolves further. The note focuses on the rationale for the design of the Netherlands model, which differs somewhat from crosssectoral supervision models introduced in some other countries, and on aspects of the implementation of the framework that are playing an important role in ensuring that the model works well in practice.

\section{Adoption of Cross-Sectoral Functional Supervision}

\section{The framework of financial sector supervision in the Netherlands is in the} process of transformation from a fairly traditional sectoral approach to a cross-sectoral functional approach. The process began in 1999 and is expected to be completed during the course of 2005. In the sectoral approach, distinct types of financial institutions are supervised by different agencies. In the cross-sectoral functional approach, two supervisory agencies focus on specific supervisory objectives, namely, the prudential objective of promoting the soundness of financial institutions (DNB-PVK), and the conduct of business objective of enhancing orderly and fair market practices (AFM).

\section{The main impetus for revamping the supervisory framework has been the} nature of the changes taking place within the Netherlands financial system. The system has come to be dominated by a few very large financial conglomerates operating in various ways across traditional sectoral lines, centralizing key risk management functions, and offering increasingly complex financial products that no longer fit neatly into traditional sectoral classifications. These trends are expected to continue, making it increasingly difficult to conduct supervision effectively or efficiently on a sectoral basis.

4. A basic strategic objective of the authorities has been to introduce a supervisory framework that will be adaptable to ongoing change in the financial sector. In this context they observed that:

"The objectives of supervision are more stable than are the institutional characteristics of financial markets, so they provide a better focal point for the organizational structure of supervision.,"2

\footnotetext{
${ }^{1}$ The principal author of this technical note is Scott Roger.

2 J. Kremers, D. Schoenmaker, and P. Wierts, 2003, “Cross-Sector Supervision: Which Model?” Brookings-

Wharton Papers on Financial Services, pp. 225-43.
} 
5. This insight suggests that organizing the supervisory framework in line with basic policy objectives will be more robust to unanticipated developments in the financial system than the traditional, sectorally-oriented framework. If the objectives of supervision were few and very distinct, then it would be fairly straightforward to design a framework in which each institution was charged with achieving a distinct objective. In reality, a major complication is the fact that the various supervisory norms and instruments underpinning the objectives of supervision are not fully distinct. In general, the various supervisory domains will contain shared elements as well as inconsistent elements. Consequently, the practical design of a supervision framework will face trade-offs between maximizing synergies among the common elements and minimizing conflicts among the inconsistent elements. Since the importance of the various tradeoffs will vary across countries with different financial systems and legal arrangements, it follows that the appropriate arrangement of objective- or functionally-oriented supervision will also vary across countries.

\section{ThE NETHERLANDS FraMeWORK}

\section{A. Steps Toward a New Framework}

6. Before 1999, cross-sectoral supervision in the Netherlands was limited to macroprudential supervision, ${ }^{3}$ carried out by the Netherlands Central Bank (DNB), ${ }^{4}$ and conductof-business supervision relating to securities market activities, carried out by the Securities Supervisor (STE) ${ }^{5}$ In 1999, the Council of Financial Supervisors (RFT) ${ }^{6}$ was established specifically to coordinate micro-prudential and conduct-of-business supervision between the sectorally-based supervisory agencies. These included DNB, responsible for supervising micro-prudential and conduct-of-business supervision of banks; the Pensions and Insurance Supervisor (PVK), ${ }^{7}$ covering pension and insurance companies; and the STE, covering securities firms. The work of the RFT highlighted the importance of cross-sectoral issues in the Netherlands and provided the primary impetus for the general re-orientation of the supervisory framework.

7. In late 2001, plans for adoption of a cross-sectoral supervisory framework were submitted to Parliament by the Finance Minister. The plan envisaged the consolidation of macro- and micro-prudential supervision into a single entity, and the establishment of a

\footnotetext{
${ }^{3}$ In this note, we use the term "macro-prudential supervision", which is common in the Netherlands. Other writers may describe the same activities as "macro-prudential surveillance", to reflect the significant differences between these activities and what is normally thought of as "supervision" in the financial sector context.

${ }^{4}$ De Nederlandsche Bank.

${ }^{5}$ Stichting Toezicht Effectenverkeer.

${ }^{6}$ Raad van Financiële Toezichthouders.

${ }^{7}$ Pensioen-en Verzekeringskamer.
} 
separate entity for conduct-of-business supervision. ${ }^{8}$ In March 2002, the STE was converted into the Authority for Financial Markets (AFM), ${ }^{9}$ taking on responsibility for conduct-ofbusiness supervision on a cross-sectoral basis, while its previous micro-prudential supervisory responsibilities for securities market activities were taken over by DNB. At the same time, DNB and PVK agreed to intensify cooperation and integration of management and activities in many micro-prudential areas, while transferring responsibility for conductof-business supervision to the AFM.

8. A crucial element in facilitating the shift toward cross-sectoral supervision was the establishment of a 'Covenant' between the DNB, PVK, and the newly-established AFM, in September 2002, to provide for close cooperation. It was recognized that the cross-sectoral approach would result in most financial firms being supervised by both prudential and conduct-of-business supervisors, with inherent dangers of overlapping and excessive regulatory burdens. The Covenant set out a basic framework for cooperation among the supervisors, including:

- Designation of a lead ("authorizing”) agency with overall responsibility for supervision (including licensing) of each financial institution and coordination of supervisory activities. DNB-PVK is the lead agency for institutions mainly in the banking, insurance, and pensions sectors, while AFM leads for securities firms;

- $\quad$ Agreement that the lead supervisor would defer to the judgment of the other supervisors in their areas of responsibility;

- $\quad$ Agreement on which aspects of a firm's management come under prudential supervision, and which come under conduct-of-business supervision;

- Rules for consultation and sharing of information between the supervisors; and

- $\quad$ Provision for annual review of the Covenant and adjustments as needed.

9. In December 2002, DNB and PVK proposed full integration of the two

institutions, which was accepted by Parliament in March 2003. In practical terms, the merger took place in May 2004, and the legal merger is scheduled to take place a little later.

10. In parallel with the changes in the institutional framework of supervision, the governing legislative framework is also being completely overhauled, with Parliamentary passage expected in 2005 .

\section{The new framework is consistent with the direction of evolving regulatory} practice in Europe. In particular, the new framework will facilitate effective supervision of

\footnotetext{
${ }^{8}$ A. Jonk, J. Kremers, and D. Schoenmaker (2002) “A new Dutch model”, The Financial Regulator, pp. 35-38.

${ }^{9}$ Autoriteit Financiële Markten.
} 
LCFIs on a consolidated basis, in line with Basel Committee principles and in line with EU policy. In addition, the framework ensures cooperation between supervisors on a cross-sector basis, consistent with EU policy.

\section{B. Design and Rationale of the Netherlands Framework}

\section{In designing the institutional framework, the authorities have carefully} considered how to best tailor it to major characteristics of the Netherlands financial sector. As a result, the framework differs in important respects from some other crosssectoral supervision frameworks. The key institutional features of the new supervisory framework in the Netherlands are:

- The consolidation of all macro- and micro-prudential supervision into a single body within the central bank (DNB-PVK);

- The consolidation of all conduct-of-business supervision within a separate body, the Authority for Financial Markets (AFM); and

- The establishment of agreements or 'covenants' between the main supervisors to ensure good coordination and cooperation. The RFT offers the two supervisors (DNB-PVK and AFM) a platform for the coordination and mutual fine-tuning of regulation and policy, especially on integrity supervision issues.

13. The decision to consolidate macro- and micro-prudential supervision in a single supervisory agency distinguishes the Netherlands' model from cross-sectoral approaches in other countries. In both Britain and Australia, for example, macro-prudential surveillance is conducted by the central bank, but micro-prudential surveillance has been taken over by separate agencies. ${ }^{10}$ The combination of both aspects of prudential supervision in the Netherlands largely reflects the fact that its financial system is dominated by a handful of large, complex financial institutions. That being the case, the distinction between microand macro-prudential issues is blurred, at least in the case of the largest institutions. The authorities observe that there are both pros and cons associated with such consolidation. On the positive side, it is likely to encourage taking greater account of macroeconomic and systemic stability considerations in micro-prudential analysis. Macroeconomic analysis is also likely to benefit by taking better account of the structure and characteristics of the financial system at the micro-level. A single macro- and micro-prudential supervisor is also seen as advantageous in the event of a financial crisis, since it would facilitate rapid assembly of essential prudential information and facilitate speedy decision-making.

\section{At the same time, it is recognized that combining macro- and micro-prudential} supervision under one roof could lead to conflicts between objectives. A particular

\footnotetext{
${ }^{10}$ It may be noted that separation of macro-prudential surveillance from micro-prudential supervision also occurs in some systems, such as Canada's, that are not explicitly based on a cross-sectoral approach.
} 
concern is that micro-prudential considerations could put increased pressure on the central bank to provide generous lender of last resort facilities, and that knowledge of this could encourage less prudent behavior by banks. In principle, this is a valid concern, but, in practice, it may not be a very significant issue in the Netherlands. This is because the DNB is only authorized to lend, including in emergency circumstances, against acceptable collateral. In practical terms, the moral hazard is that the DNB might be willing to offer slightly better terms on offered collateral than it might otherwise do. That is unlikely to promote significantly riskier behavior by financial institutions.

\section{With the financial system dominated by very large banks, the failure of any of} them would have a major impact on the Netherlands economy. In such circumstances, there is likely to be a view that the main banks, at least, are "too large to fail," whether or not micro- and macro-prudential supervision is consolidated in one institution. In other words, the Dutch taxpayer is already at risk, and integrating macro- and micro-prudential supervision will make little real difference. ${ }^{11}$

\section{It could be argued that the risk to the taxpayer might actually be reduced by} consolidating macro- and micro-prudential supervision in one entity. Given the difficulty of credibly pre-committing to not bail out any of the major banks in the Netherlands, the authorities' response appears, essentially, to involve supervising financial institutions more closely than might otherwise be the case, in order to reduce the risk of bank failures. If consolidation of prudential supervision leads to improvements in the quality of supervision, this should, in principle, reduce the probability of bank failures and bailouts.

\section{An additional issue in relation to the consolidation of macro- and micro-} prudential supervision is whether this should be located within the central bank. The fact that the DNB is no longer responsible for conducting an independent monetary policy undercuts one of the traditional arguments in favor of locating prudential supervision outside the central bank, because the scope for conflict of interest between monetary policy and prudential policy objectives is largely eliminated. In addition, the Netherlands authorities suggest, on the basis of some international experience, that a fully separate prudential supervisor could be very vulnerable to criticism in the event of a bank crisis or failure. From this perspective, a supervisor 'sheltered' by the authority and credibility of the central bank may be in a stronger position to act decisively or to take unpopular decisions.

18. The authorities are also well aware of the need to avoid another potential risk by ensuring that micro-prudential supervision does not under-cut the attention paid to macro-prudential issues. The high public and political profile attached to the stability of

\footnotetext{
${ }^{11}$ The Netherlands' system of deposit insurance potentially involves substantial taxpayer exposure: deposit coverage is broad and the system is not pre-funded. In theory, the DNB would make initial payouts under the insurance system, to be recouped over time from the remaining banks. While this would work for a small bank failure, it might be very difficult for the DNB (and ultimately the taxpayer) to recoup its layouts in the event of a large bank failure. The system of deposit insurance is currently under review, though separately from the revision of financial sector supervision and legislation.
} 
individual financial institutions bears with it the risk that resources and attention devoted to this aspect of prudential supervision could lead to neglect of macro-prudential activities. This highlights the importance of ensuring that the integration of these kinds of supervision be accompanied by high levels of transparency and accountability, to ensure that both kinds of considerations are given proper weight. One important way in which the DNB-PVK is addressing this issue is through the establishment of a separate, focused Financial Stability Department to take the macro-prudential work forward in coordinated fashion. Although the new department may not directly raise the public profile of systemic stability issues in the shorter term (because DNB-PVK already published quality macro-prudential analyses), the organizational change creates a stronger incentive and accountability framework to develop this work further over time. And in the meantime, it is likely to help raise further the profile of these issues in the context of micro-prudential analysis.

19. Moreover, in order to carry out effective macro-prudential analysis right across the financial sector, significant improvements in some key data are likely to be needed. For example, better data from the insurance and pension sectors will be required (notably in terms of frequency and timeliness), as also in some aspects of banking data (e.g., sectoral analyses), and more integration of risk analysis frameworks used for the different types of institutions. At the same time, however, better data in key areas will need to be balanced against the need to reduce unnecessary administrative burdens for supervised institutions, an objective reflected in a specific program of the Dutch government. European-level initiatives in this area, including streamlined data collection under the EU Directive on supervision of financial conglomerates, may facilitate achieving a reasonable balance here.

\section{The second major feature of the Netherlands framework is the separation of} prudential supervision from conduct-of-business supervision. This separation is also a feature of the Australian cross-sectoral framework. By contrast, in the British cross-sectoral framework, both types of supervision are conducted by the Financial Services Authority (FSA), reflecting the common objectives in certain areas and the operational synergies the authorities perceived between these activities. The Netherlands authorities, however, emphasize basic differences in micro-prudential and conduct-of-business objectives as the main reason for separating the two types of supervision. In the case of micro-prudential supervision, the primary objective is to ensure the soundness of financial institutions. In the case of conduct-of-business supervision, it is argued that the primary objective is the promotion of orderly and fair financial market practices, with particular attention to the relationships between financial institutions and their clients. Given these differences, significant conflicts between objectives could arise, suggesting that supervision in the two domains be separate. The case for separation may be reinforced by observing that potential synergies between these two kinds of supervision may be limited.

21. The case for separating prudential and conduct-of-business supervision is valid, but as in any such choice there are trade-offs to be struck, and the implications of the choices have to be managed. In this case, the potential advantages in terms of institutional focus, transparency and accountability of having separate organizations pursuing distinct policy objectives must be weighed against potential disadvantages in terms of foregone 
synergies between the organizations, and reduced flexibility in shifting resources, including skilled staff, between the different areas of supervision. The net advantages of division will be greater the more distinct are the policy objectives, the less fungible in general are the skills or knowledge in the two areas, and the better the arrangements for co-operation in areas where interests and skills are complementary. At the same time, the judgment of where the trade-off is best struck also has to consider whether, in a combined prudential and conductof-business supervisor, strong transparency and accountability arrangements could mitigate the disadvantages of mixed policy objectives, so that supervisors still make intelligent tradeoffs or compromises. Furthermore, such trade-offs are probably not independent of the tradeoffs taken in deciding how to allocate the macro- and micro-prudential supervision functions. In short, such judgments are not necessarily straightforward, as is illustrated by the range of practice that currently exists in the (relatively) new institutional arrangements internationally. Time will tell whether, empirically, one form of arrangement is more generally applicable than others.

\section{Given their own circumstances, the Dutch authorities have considered such} trade-offs, and judged that the gains from potential synergies from combining prudential and conduct-of-business supervision do not outweigh the disadvantages of

doing so. Furthermore, there appears to be another pragmatic reason for separating prudential from conduct-of-business supervision based on differences in supervisory approaches, particularly in the area of enforcement. The authorities note that for prudential supervision, a premium is put on discretion and confidentiality, both to promote cooperation of financial institutions and to avoid shaking public confidence in them. In the case of conduct-ofbusiness supervision, it is not only important for the supervisor not only to promote fairness in the treatment of consumers of financial services, but also to be seen to be doing so, and this generally requires an approach to supervision that is more visible to the public. Reconciling such differences in approach may be difficult within one institution (unless the functions are effectively separated within the institution), and could undermine the credibility of both types of supervisors. Moreover, it is probable, given the relatively high public profile of conduct-of-business issues, that combining them with prudential supervision issues in the same institution would distract resources and management attention from prudential supervision.

\section{Making The Model Work}

23. In short, then, the Dutch variant of the cross-sectoral framework is well thought out, well suited to the circumstances of the Dutch market, and appears likely to enhance the flexibility and efficiency of supervision. Although the design of the framework is tailored to the specific situation of the Netherlands, it should be relevant for other countries considering the adoption of cross-sectoral supervision, especially where financial systems are dominated by LCFIs. Strengthening the incentives for effective prudential supervision, including minimizing the scope for management distraction or conflicting objectives, is all the more relevant where such LCFIs are highly systemically important, so that "dropping the ball" in prudential supervision of such institutions could be even more damaging than would otherwise be the case. Nonetheless, with the adoption of the cross-sectoral supervision 
framework, two particular kinds of problems could be expected to arise, and have to be managed. These include problems specific to the transition between supervision frameworks, as well as problems that may be inherent in the functional element of the cross-sectoral framework.

\section{The changes in the supervisory framework in the Netherlands entail substantial} changes in bureaucratic duties and organization for each of the supervisory agencies. The authorities appear to have been very careful to introduce the changes in a gradual manner; they have avoided a 'big bang'. Drawing partly on the authorities' interpretation of experience elsewhere, the integration of the DNB and PVK has progressed very deliberately. DNB and PVK began integration at a high level, through cross-appointments at management level. Close cooperation and coordination of activities has also been provided through the Covenant discussed earlier.

\section{Even after integrated supervision began in May 2004, however, the intention is} not to move to a fully-integrated cross-sectoral approach in all areas right away. Initially, the DNB-PVK is establishing some joint departments, notably including the new Financial Stability Department and the Supervision Policy Department. As already noted, it is anticipated that the early establishment of the Financial Stability Department will help sharpen the monitoring and analysis of macro-prudential indicators at the operational level, and that this will then feed through into analysis and public reporting at a more aggregated level.

26. Operational supervision will not be fully integrated at the outset. In effect, aside from the largest groups, PVK will continue to provide prudential supervision of pensions and insurers, while DNB will continue to focus on banks and securities firms. This will provide an important element of stability or continuity for the institutions, as well as for the financial firms being supervised. The use of integrated teams to cover the LCFIs from the outset, however, may well facilitate integration of supervision at the operational level, in so far as it will bring together personnel with significant shared knowledge, and also, perhaps, significant previous experience of cooperation. In addition, integration of supervision on a team-by-team basis offers the potential for experimentation and to tailor the pace of integration to the needs and capacity of the particular teams.

\section{The metamorphosis of the securities supervisor, STE, into the conduct-of-} business supervisor, AFM, is probably the most substantial institutional make-over. A major effort has been required to develop its supervisory framework, at the same time as it has seen a rapid increase in staffing. Inevitably, growing pains are bound to be experienced as the AFM itself goes up an institutional learning curve, as well as by the financial institutions being supervised by the AFM, and by the other supervisory agencies giving up their responsibilities for conduct-of-business supervision. So the fact that there have been industry complaints, particularly regarding the activities of the AFM is not very surprising. What is more important is the nature of the problems and how they are addressed. It might be helpful for the authorities to clarify for financial institutions the reasons for the differences in 
approaches taken by different supervisors and to reassure them that AFM is operating in accordance with international standards and is subject to proper safeguards.

28. Some of the complaints with the AFM concern its style which, as noted earlier, tends to be less confidential than the style that the financial institutions are used to. In all likelihood, this is a transitional problem; financial institutions will get more accustomed to AFM's different approach, and AFM may also modify its style over time in a way that financial institutions are more comfortable with.

\section{There have also been concerns raised regarding overlapping supervision by}

AFM and DNB-PVK. Again, there may be a transitional element to this, but it also points to what will probably be an ongoing challenge in the functional approach to supervision. The functional approach means that there will be more than one supervisor for most financial institutions. This can result in supervisory overlap if coordination is weak. Of course, overlaps can occur within a single supervisor if internal coordination is weak. To avoid the inefficiencies associated with supervision overlaps, it is important to ensure, in the first instance, that the supervisors have very clear mandates, and that these are made clear to those being supervised. The revision to supervision legislation is expected to provide such clarification at a higher level at least. One key matter to clarify will be the respective powers of the two supervisory authorities to grant, withhold or revoke licenses. It is important that, within the concept of lead regulator, either regulator can take licensing decisions where necessary to uphold the regulatory standards for which they are responsible.

\section{In addition, it is essential to establish a process for regular consultation and} review in order to minimize such problems if they arise. Moreover, since the financial system and the activities of players evolve, coordination of supervision is bound to be a moving target. The RFT clearly has an important role to play in ensuring close coordination between the supervisory agencies on a routine basis. In addition, however, it will be important to have a less frequent, but more comprehensive review process. In this regard, the review of the Covenant between AFM, DNB and PVK currently underway may serve as a model for the future. Although part of the motivation is to replace the trilateral Covenant with a bilateral successor between DNB-PVK and AFM, the review offers the opportunity to take stock of developments over time, as well as to solicit and take into account the views of supervised firms and other interested parties, in modifying supervisors' activities. This element of the framework should be seen as an essential ingredient in ensuring the efficiency and flexibility of the new supervisory framework. Given its importance, the review process should probably be formalized, and the substance of the agreement made readily available to the public. 